\title{
Efficacy Analysis and Kinetics of 3-Component Photopolymerization by Visible-LED/Coumarin and Enhanced by Additives of Iodonium Salt and Amine
}

\author{
Jui-Teng Lin ${ }^{1, *}$, Jacques Lalevee ${ }^{2}$ and Da-Chun Cheng ${ }^{3, *}$ \\ . ${ }^{1}$ New Vision Inc., 10F, No. 55, Sect.3, Xinbei Blvd, Xinzhuang, New Taipei City, Taiwan; \\ jtlin55@gmail.com
}

2 Université de Haute-Alsace, CNRS, IS2M UMR 7361, F-68100 Mulhouse, France; jacques.lalevee@uha.fr

- 3 Department of of Biomedical Imaging and Radiological Science, China Medical University, 404, Taiwan, ROC; dccheng@mail.cmu.edu.tw

*Correspondences: jtlin55@gmail.com; dccheng@mail.cmu.edu.tw

\begin{abstract}
This article presents, for the first time, the kinetics and the general conversion features of free radical polymerization (FRP) in a 3-component system $(\mathrm{A} / \mathrm{B} / \mathrm{N})$, with $[\mathrm{A}]$ being the initiator, and $[\mathrm{B}]$ and $[\mathrm{N}]$ are additives, based on the proposed mechanism of Rahal et al. Higher FRP can be achieved by additives [B] and [N], via the dual function of (i) regeneration [A], and (ii) generation of extra radicals $(\mathrm{R})$ via the radicals ( $\mathrm{S}$ ' and $\mathrm{S}$ ) produced by $\mathrm{N}$. The initiator (coumarin) shows a dual photo-oxidation and photo-reduction character for high efficacy. The FRP conversion efficacy (CE) depends not only on the property of the initiator $[\mathrm{A}]$, the additives $[\mathrm{B}]$ and $[\mathrm{N}\}$, but also the types of monomers. For example, when $[A]=$ CoumC, $[A] / N P G$ is more efficient than $[A] / I o d$, but revserse trend occurs in some monomers. However, 2-component systems (with $\mathrm{CE}=0 \%$ to $80 \%$ ) are always less efficient than that of 3-component systems (with $\mathrm{CE}=70 \%$ to $86 \%$, in TMPTA). Specific systems with $[\mathrm{A}]=$ coumarins, $[\mathrm{B}]=$ Iodonium salt, and N=NPG are analyzed. Analytical formulas for the role of each component concentration, light intensity and coupling rates on the conversion efficacy are derived.
\end{abstract}

Keywords: polymerization kinetics; photoinitiator; free radical polymerization;photo-oxidation; 3D printing.

\section{Introduction}

Photopolymerization using light sources from UV ( $365 \mathrm{~nm})$ to near-infrared $(980 \mathrm{~nm})$ have been used in many industrial and medical applications such as dental curing, microlithography, stereolithography, microelectronics, holography [1,2]. Variety of photoresponsive materials such as conjugated polymers have been reported for additive manufacturing (AM) and recently for $3 \mathrm{D}$ and $4 \mathrm{D}$ bioprinting [3-8]. Both spatial and temporal controlled 3D processes were reported using single and multiple wavelength lights [6-8]. We have reported the kinetics and efficacy analysis for various strategies for improved conversion, such as co initiators, co additives in both single and multiple components systems [9-11].

Photochemical polymerization uses ultraviolet (UV) radiation has been widely known as UV curing. However, the UV light is harmful to human health (carcinogenic) and characterized by particularly low light penetration, which is a challenge for the photopolymerization of thick and filled 
samples [11]. Organic dyes used as visible light photosensitizers of polymerization have been extensively studied $[11,12]$, in which high extinction coefficients and their long-living excited states, enabling the photosensitizers to react efficiently with various additives in the photocurable resins. For cost effective with long-living excited states, copper complexes have been used as a new polymerization approach enabling the formation of acetylacetonate radicals by redox reaction with a phosphine and to initiate the free radical polymerization (FRP) of acrylates or the free radical promoted cationic polymerization (CP) of epoxides [13-16]. More recently, coumarin as dual function of photoinitiators in photo-oxidation or photo-reduction in visible light were reported [17-19]. These dyes are characterized by very high extinction coefficients with a broad absorption extending over the near UV/visible and high quantum yields [12]. These hotoinitiators can be used in 3D printing experiments with a very high efficiency in the photocomposite synthesis (significant curing of the surface and the bottom) using a LED at $405 \mathrm{~nm}$ [12]. Many of the reported experiments were theoretically studied by Lin et al, including dual and three-wavelength systems [9,10, 20-22].

This article will present, for the first time, the kinetics and the general conversion features of the 3-component ([A]/ [B]/[N]) system based on proposed mechanism of Rahal et al [19]. The roles of coadditives $[\mathrm{B}]$ and $[\mathrm{N}]$ include their dual functions of regeneration of initiator $[\mathrm{A}]$ and radicals for improved conversion. The key factors influencing the conversion rates and efficacy will be explored by analytic formulas derived from a kinetic model for a 3-component system. Finally, the measured data of Rahal et al [19] will be quantitatively analyzed by our analytic formulas, rather than their qualitative discussions.

\section{Methods and Modeling Systems}

\subsection{Photochemical Kinetics}

As shown by Scheme 1, proposed by Rahal et al [19] for a three-component system. The photoinitiator (Coumarin) is excited by a LED light to its excited state which then couples with the Iod salt (or NPG), and dissociates and give reactive species responsible to initiate the FRP (r1-r2). A charge-transfer complex between Iod salt and NPG [Iod-NPG] is able to generate reactive species (r3$\mathrm{r} 4)$. Moreover, a hydrogen transfer process from NPG to Coumarins can occur ( $\mathrm{r} 5$ ) which generates two types of radicals $($ Coum- $\mathrm{H} \bullet$ ) and NPG(-H) $\bullet$, which can decarboxylate and lead to the radical formation (NPG(-H, $-\mathrm{CO} 2) \bullet$ ), which reacts with Iod salt to produce reactive species (Ar• and NPG($\mathrm{H}, \mathrm{CO} 2)+)(\mathrm{r} 6-\mathrm{r} 7)$. Ar• and NPG(-H,-CO2)•) (r1-r9) radicals are assumed as the reactive species responsible to the FRP of the (meth)acrylate functions. The measured coumarins consumption is reduced in three-component system [19] can be explained by a regeneration of the photoinitiator, shown in r7, r10, r12 and r13.

\begin{tabular}{|c|c|c|c|}
\hline Coumarin + light & $--->$ & Coumarin* & (r1) \\
\hline Coumarin $*+\mathrm{Ar}_{2} \mathrm{I}^{+}$ & $--->$ & $\mathrm{Ar}^{\mathrm{o}}+\mathrm{ArI}+$ Coumarin $^{*+}$ & $(\mathrm{r} 2)$ \\
\hline $\mathrm{NPG}+\mathrm{Iod}$ & $--->$ & {$[\text { NPG-Iod }]_{\mathrm{CTC}}$} & $(\mathrm{r} 3)$ \\
\hline$[\text { NPG-Iod }]_{\text {СTC }}+$ Light & $--->$ & $\operatorname{Ar}^{\circ}$ & $(\mathrm{r} 4)$ \\
\hline Coumarin* + NPG & $--->$ & Coumarin- $\mathrm{H}^{\mathrm{o}}+\mathrm{NPG}_{(-\mathrm{H})}^{\mathrm{o}}$ & $(\mathrm{r} 5)$ \\
\hline $\mathrm{NPG}_{(-\mathrm{H})}{ }^{\mathrm{o}}$ & $--->$ & $\mathrm{NPG}\left(-\mathrm{H} ;-\mathrm{CO}_{2}\right)^{\mathrm{O}} \quad+\mathrm{CO}_{2}$ & $(\mathrm{r} 6)$ \\
\hline Coumarin- $\mathrm{H}^{\mathrm{o}}+\mathrm{Ar}_{2} \mathrm{I}^{+}$ & $--->$ & Coumarin $+\mathrm{Ar}^{\mathrm{O}}+\mathrm{ArI}+\mathrm{H}^{+}$ & $(\mathrm{r} 7)$ \\
\hline $\mathrm{NPG}\left(-\mathrm{H} ;-\mathrm{CO}_{2}\right)^{\mathrm{o}}+\mathrm{Ar}_{2} \mathrm{I}^{+}$ & $--->$ & $\mathrm{NPG}\left(\mathrm{CO}_{2}\right)^{\mathrm{o}}+\mathrm{Ar}^{\mathrm{o}}+\mathrm{ArI}+\mathrm{H}^{+}$ & (r8) \\
\hline $\mathrm{Ar}^{\mathrm{O}}+{ }^{3} \mathrm{O}_{2}$ & $--->$ & $>\quad \mathrm{ArO}_{2}+{ }^{1} \mathrm{O}_{2}$ & $(\mathrm{r} 9)$ \\
\hline Coumarin* $+{ }^{3} \mathrm{O}_{2}$ & $--->$ & Coumarin $+{ }^{1} \mathrm{O}_{2}$ & $(\mathrm{r} 10)$ \\
\hline $\mathrm{Ar}^{\mathrm{O}}+$ Monomer & $---->$ & Polymer + Coumarin & (r11) \\
\hline Coumarin* + Monomer & $--->$ & Polymer + Coumarin & $(\mathrm{r} 12)$ \\
\hline
\end{tabular}


${ }^{1} \mathrm{O}_{2}+$ Monomer $\quad$---> $\quad$ Polymer $+\mathrm{MO}$

Scheme 1. Kinetic scheme for a 3-component system (Coumarin/Iod/NPG)[19].

The above described Scheme 1 is further expressed by our kinetic chart using the simplified notations for the concentration of each species: [A] for initiator Coumarin (ground state), which is excited to a triplet state $[\mathrm{T}\} ;[\mathrm{B}]$ for additive Iod (or $\mathrm{Ar}_{2} \mathrm{I}^{+}$); $[\mathrm{C}]$ for Coumarin* (in r2); [N] for NPG, and radicals $\mathrm{R}, \mathrm{S}$ and $\mathrm{S}^{\prime}$ are, respectively, for Aro, Coumarin- $\mathrm{H}^{\circ}$ (in r2) and $\mathrm{NPG}\left(-\mathrm{H},-\mathrm{CO}_{2}\right)^{\circ}$ (in $\mathrm{r} 7$ ). Regeneration of initiator [A] is shown in $\mathrm{r} 8$ and $\mathrm{r} 9$. The oxygen inhibition effects are shown in $\mathrm{r}$; ; and coupling of Coumarin* and oxygen procing singlet oxygen is shown in $\mathrm{r} 10$; the monomer conversions due to $\mathrm{T}, \mathrm{R}$ and singlet oxyegn are shown in $\mathrm{r} 11$ to $\mathrm{r} 13$. Above Scheme did not show the radical termination couplings of $R$ and $R, R$ and $S, R$ and $S$, which will be included in our next kinetic chart, Fig. 1, and our rate equations.

As shown by Figure 1, a 3-components system $(\mathrm{A} / \mathrm{B} / \mathrm{N})$ defined by the ground state of initiator- $\mathrm{A}$, which is excited to its triplet excited state $\mathrm{T}$, having a quantum yield (q). The triplet state $\mathrm{T}$ interacts with additive [B] (Iod) to produce radical $\mathrm{R}$, and oxodized-A (or [C]), which could interact with the additive N (NPG) to regenerate initiator [A]. In addition, T could interact with additive $N$ producing radical $S$ and $S^{\prime}$, which couple with $[B]$ to produce more radical $R$ and regenerate initiator [A]. Both $\mathrm{T}$ and radical (R) could couple with the monomer for FRP. We have also shown the oxygen inhibition effects due to the coupling of $R$ and singlet oxygen $\left({ }^{1} \mathrm{O}_{2}\right)$, produced by the coupling of $\mathrm{T}$ and ground state oxygen, $\left[{ }^{3} \mathrm{O}_{2}\right]$. The radical termination couplings (not shown in Fig.1) of R and R, R and S, R and S' will be included in our kinetic equations. Greater details about the role of oxygen was publishd by Lin et al [25]. We note that $\mathrm{T}, \mathrm{R}$ and ${ }^{1} \mathrm{O}_{2}$ couple with the monomer for FRP conversion.

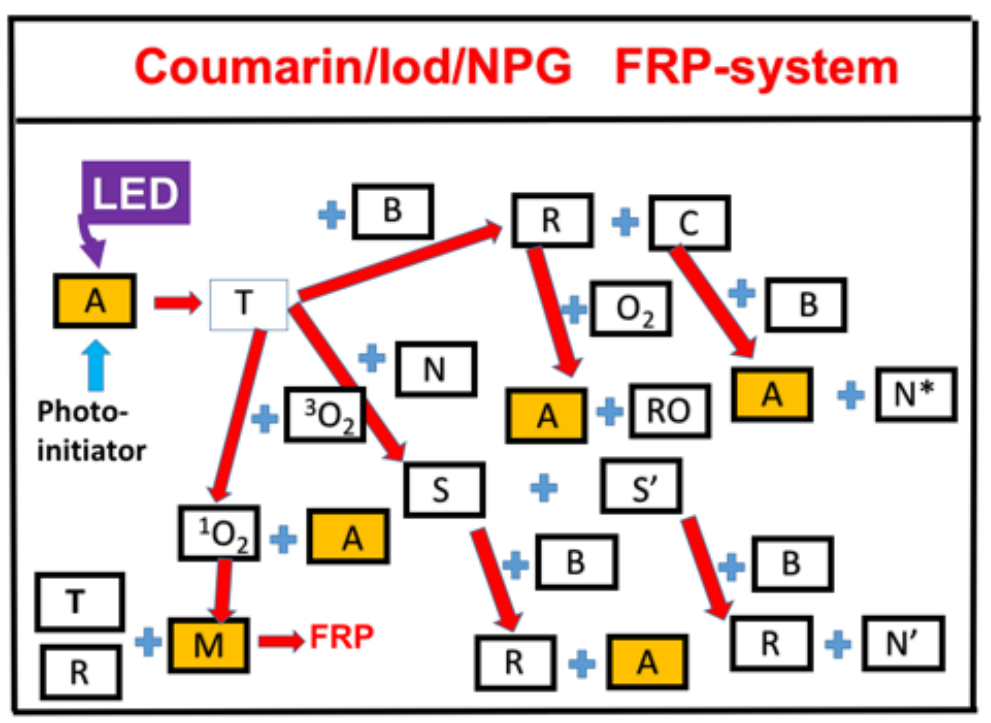

Figure 1. The schematics of a 3-components system $(\mathrm{A} / \mathrm{B} / \mathrm{N})$ defined by the ground state of initiator[A], which is excited to its triplet excited state $\mathrm{T}$. The triplet state $\mathrm{T}$ interacts with additive [B] (to produce radical $\mathrm{R}$, and $[\mathrm{C}]$, which could interact with the additive $[\mathrm{N}]$ to regenerate initiator $[\mathrm{A}]$. In addition, $T$ could interact with additive $N$ producing radical $S$ and $S^{\prime}$, which couples with [B] to produce more radical $\mathrm{R}$. The interaction of oxygen and $\mathrm{T}$ produces singlet oxygen. The FRP is due to the coupling of $T, R$ and singlet oxygen with the monomer (M). Other couplings are discussed in the text.

The kinetic equations for our previous systems [21-25] are revised for the above 3-component system $(\mathrm{A} / \mathrm{B} / \mathrm{N})$ as follows, using the short hand notation $\mathrm{X}$ for singlet oxygen. 
$\frac{d[A]}{d t}=-b I[A]+R E G$

$\frac{d[B]}{d t}=-\left(k_{2} T+k_{4} S+k_{5} S^{\prime}+k_{6}[C]\right)[B]$

$\frac{d[N]}{d t}=-k_{3} T[N]$

$\frac{d[C]}{d t}=k_{2}[B] T-k_{6}[B][C]$

$\frac{d T}{d t}=b I[A]-\left(k_{7}+k_{2}[B]+k_{3}[N]+k M+k_{8}\left[O_{2}\right]\right) T$

$\frac{d R}{d t}=\left(k_{2}[B]+k M\right) T+\left(k_{4} S+k_{5} S^{\prime}\right)[B]-\left(k^{\prime} R+k^{\prime \prime} S+k^{\prime \prime} S^{\prime}+K^{\prime \prime}\left[O_{2}\right]+K M\right) R$

$\frac{d S}{\partial t}=k_{3}[N] T-\left(k_{4}[B]+k^{\prime \prime} R\right) S$

$\frac{\partial S^{\prime}}{\partial t}=k_{3}[N] T-\left(k_{5}[B]+k^{\prime \prime} R\right) S^{\prime}$

$\frac{\partial X}{\partial t}=k_{8}\left[O_{2}\right] T-\left(k_{9}+k_{1}[A]+K^{\prime} M\right) X$

$\frac{\partial\left[O_{2}\right]}{\partial t}=P-k_{8}\left[O_{2}\right] T-K^{\prime \prime}\left[O_{2}\right] R+k_{6} X$

The regeneration of initiator $[\mathrm{A}]$ is given by

$R E G=\left(k_{7}+k M\right) T+k_{4} S[B]+k_{6}[C][B]+K^{\prime \prime}\left[O_{2}\right] R+k_{8}\left[O_{2}\right] T-k_{1}[A] X$

The monomer $(\mathrm{M})$ conversions for FRP is given by $[21,23]$

$\frac{d M}{d t}=-\left(k T+K R+K^{\prime} X\right) M$

where the light couplig constant $\mathrm{b}=83.6 a^{\prime} w q$, with $w$ being the light wavelength (in $\mathrm{cm}$ ) and $q$ is the triplet state T quantum yield; $a^{\prime}$ is the mole absorption coefficient, in $(1 / \mathrm{mM} / \%)$ and $\mathrm{I}(\mathrm{z}, \mathrm{t})$ is the light intensity, in $\mathrm{mW} / \mathrm{cm}^{2}$, which in general is time ( $\mathrm{t}$ ) and spatial (or olymer thickness, $\mathrm{z}$ ) dependent. All the rate constants are defined previously [22] and they are related by the coupling terms. For examples, $k_{j}$ (with $j=1,2,3$ ) are for the couplings of $T$ and $[A],[B]$, and $[C]$, respectively; $T$ has a relaxation rate of $\mathrm{k}_{7} ; \mathrm{k}_{4}$ and $\mathrm{k}_{8}$ are for the couplings of $S$ and $[\mathrm{B}]$; and $\mathrm{S}$ and [B], respectively.

The importnat features of above kinetic equations are summarized as follows.

(i) The regeneration term (REG) of the initiator, [A], shown by Eq. (11) has 5 components: relaxation

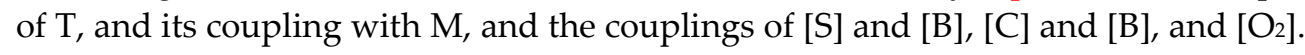

(ii) The additive component, [B] (or Iod), has triple functions of: (a) regeneration of [A] via its coupling with [C]; (b) direct producing of radical (R) via its coupling with T; and (c) indirect producing of radical $(\mathrm{R})$ via its coupling with the radicals ( $\mathrm{S}$ and $\mathrm{S}^{\prime}$ ) produced by another additive $[\mathrm{N}]$ (or PNG).

(iii) Similarly, the additive [N] (or Iod) aslo produces radical $\mathrm{R}$, but indirectly via the coupling of radicals $\left(\mathrm{S}\right.$ and $\mathrm{S}^{\prime}$ ) and $[\mathrm{B}]$. Therefore, $\mathrm{A} /[\mathrm{N}]$ (without $[\mathrm{B}]$ ) has smaller FRP than $\mathrm{A} / \mathrm{Iod}$ in many monomers conversions, as reported by Rahal et al [19]. As shown mathematically by Eq. (6) that $\mathrm{R}$ is small, when $[B]=0$ which leads to $S=S^{\prime}=0$.

(iv) The conversion efficacy (CE), defined by $C E=1=M / M_{0}$, is given by the time integral of the rate function of Eq. (12), given by 3 terms, $R_{T}=k T+K R+K^{\prime} X$, contributed from the type-I FRP, or direct 
coupling with triple state (T); and the type-II FRP, or coupling of T with the additives ( $[\mathrm{B}]$ and $[\mathrm{N}]$ ) produced radical $(\mathrm{R})$, and the oxygen induced singlet oxygen $\mathrm{X}$. In most systems, type-II is dominated (for $\mathrm{k}<<\mathrm{K}$ ).

(v) The oxygen inhibition effects (OIE), given by $\mathrm{k}_{8}\left[\mathrm{O}_{2}\right]$ and $\mathrm{K}^{\prime}\left[\mathrm{O}_{2}\right]$, in Eq. (5) and (6), are important for system in air [22]. We note that $\mathrm{g}$, $\mathrm{g}$ ' and radical $(\mathrm{R})$ are decreasing fuction of $\left[\mathrm{O}_{2}\right]$ due to OIE. For laminate system or when $\mathrm{T}$ or $\mathrm{R}$ is insensitive to oxygen, the OIE may be neglected. In Eq. (6), we have included the radical terminations given by the bimolecular termination ( $R$ and $R$ ), and $R$ and $S^{\prime}$ and S. But we have ignored other coupling among $R$ and $[A]$. $[B]$, or $[C]$, because our main focus is to explore the synergic effects of $[\mathrm{B}]$ and $[\mathrm{N}]$.

For comprehensive modeling we will use the so-called quasi-steady state assumption [23]. The life time of the singlet and triplet states $(T)$, and the radicals (R, $S^{\prime}$ and $\left.S\right)$, since they either decay or react with the monomer immediately after they are created. We also assume the steady state of singlet oxygen which strongly couples with theradical (R). Thus, one may set $\mathrm{dT} / \mathrm{dt}=\mathrm{dR} / \mathrm{dt}=\mathrm{dS} / \mathrm{dt}=$ $\mathrm{dS} / \mathrm{dt}=\mathrm{d}[\mathrm{C}] / \mathrm{dt}=\mathrm{dX} / \mathrm{dt}=0$, which give the quasi-steady-state solutions [25]: $\mathrm{T}=\mathrm{bIg}[\mathrm{A}], \mathrm{R}=\mathrm{bIg}[\mathrm{A}] \mathrm{g}^{\prime}[($ $\left.\mathrm{k}_{2}+\mathrm{kM}+\mathrm{K}^{\prime \prime}\left[\mathrm{O}_{2}\right]+2 \mathrm{k}_{3} \mathrm{k}_{4}\left(\mathrm{~g}^{\prime \prime} / \mathrm{g}^{\prime}\right)[\mathrm{N}]\right)$ [B]], if ignored $\mathrm{k}^{\prime} \mathrm{RR}, \mathrm{k} " \mathrm{RS}, \mathrm{k}^{\prime \prime} \mathrm{RS}$ term in Eq. (6); $\mathrm{S}=\mathrm{S}^{\prime}=\mathrm{k}_{3} \mathrm{bIgg}$ "[A][N] ( for $\left.\mathrm{k}_{4}=\mathrm{k}_{5}\right) ;[\mathrm{C}]=\left(\mathrm{k}_{2} / \mathrm{k}_{6}\right) \mathrm{bIg}[\mathrm{A}] ; \mathrm{X}=\mathrm{g}^{\prime \prime} \mathrm{k}_{8}\left[\mathrm{O}_{2}\right] \mathrm{T}$; and $\mathrm{g}=1 /\left(\mathrm{k}_{7}+\mathrm{k}_{2}[\mathrm{~B}]+\mathrm{k}_{3}[\mathrm{~N}]+\mathrm{kM}+\mathrm{k}_{8}\left[\mathrm{O}_{2}\right]\right)$, $\mathrm{g}^{\prime}=1 /\left(2 \mathrm{k}^{\prime \prime} \mathrm{S}+\mathrm{KM}+\mathrm{K}^{\prime \prime}\left[\mathrm{O}_{2}\right]\right), \mathrm{g}^{\prime \prime}=1 /\left(\mathrm{k}_{4}[\mathrm{~B}]+\mathrm{k}^{\prime \prime} \mathrm{R}\right), \mathrm{g}^{\prime \prime}=1 /\left(\mathrm{k}_{6}+\mathrm{K}^{\prime} \mathrm{M}\right)$. We note that $\mathrm{g}$, $\mathrm{g}^{\prime}$ and radicals $\left(\mathrm{R}, \mathrm{S}, \mathrm{S}^{\prime}\right)$ are are decreasing fuction of [ $\left.\mathrm{O}_{2}\right]$ due to OIE [25]. In above solutions, we have ignored k'RR, k"RS, k"RS' term in Eq. (6) fr the case on unimolecular coupling. We note that for the bimolecular coupling case of $\mathrm{k}^{\prime} \mathrm{R}^{2}$, the solution of $\mathrm{R}$ is proportinal to the squre-root of, bI[A], a much more complext case which was published by Lin et al [23].

Under the above quasi-steady-state solutions, we obtain the simplified equations as follows.

$\frac{\partial[A]}{\partial t}=-b I[A]\left(1-R_{G}\right)$

$\frac{\partial[B]}{\partial t}=-2 b \operatorname{Ig}[A]\left(k_{2}+k_{4} k_{3} g^{\prime \prime}[N]\right)[B]$

$\frac{\partial[N]}{\partial t}=-k_{3} b \operatorname{Ig}[A][N]$

The regeneration of initiator [A] in Eq. (13) is reduced to

$1-R_{G}=k^{\prime \prime} R S-\left(k_{9} X+K M X+K^{\prime \prime}\left[O_{2}\right] R\right)$

The monomer (M) conversions for FRP is given by [20]

$\frac{d M}{d t}=-b \operatorname{Ig}[A]\left(k+K Q[B]+K^{\prime} X\right) M$

where $Q(t)=g^{\prime}\left[\left(k_{2}+k M+K^{\prime \prime}\left[\mathrm{O}_{2}\right]+2 k_{3} k_{4}\left(g^{\prime \prime} / g^{\prime}\right)[N]\right)[B]\right]$.

\section{3.. Results and discussion}

A full numerical simulation is required for the solutions of Eq. (13)-(17), which will be presenetd elasewhere. We will focus on comprehensive analysis for new features and the enhancement effects related to the measured data of Rahal et al [19], based on the analytic formulas.

\subsection{Analytic results}

For analytic formulas and focusing on the enhanced effects of $[\mathrm{B}]$ and $[\mathrm{N}]$, we will ignore the oxygen effects, i.e., $X=0$, in the following discussions. Using our previously developed approximated analytic formulas [22] for the light intensity and solving for Eq. (13)-(17), we obtain the analytic forms, 
for approximated value of $[\mathrm{A}]=\mathrm{f}^{\prime} \mathrm{A} 0$ with $\mathrm{f}^{\prime}=0$ to 0.5 , is a correction factor; and $[\mathrm{N}]=[\mathrm{N}]_{0} \exp (-\mathrm{dt})$, $d=f^{\prime}\left(k_{3} / k_{1}\right) b I_{0}$ and $g^{\prime \prime}=1 /\left(k_{4}[B]_{0}\right)$, and for strong regeneration case with $[A]=$ constant $=f^{\prime}[A]_{0}$,

$$
\begin{aligned}
{[B] } & =[B]_{0} \exp \left(-d^{\prime} t\right)\left[1+2 b I_{0} k_{3}[N]_{0} E(t)\right] \\
E(t) & =\left[1+\exp \left(-d^{\prime \prime} t\right)\right] / d^{\prime \prime}
\end{aligned}
$$

where $\left.d^{\prime}=f^{\prime}\left(k_{2} / k_{1}\right) b I_{0}, d^{\prime \prime}=d-d^{\prime}=\left(k_{3}-k_{2}\right) / k_{1}\right) b I$; which, for small $t, B(t)=(1+G t)[B] 0$ exp $\left(-d^{\prime} t\right)$, with $G=\left(2 b I_{0}\right.$ $\left.\mathrm{k}_{3}\right)[\mathrm{N}]_{0}$.

Eq. (17) may be solved to give the conversion efficacy (CE) defined by $C E=1-\mathrm{M} / \mathrm{M}_{0}=1-\exp (-\mathrm{E} ")$, where the $E^{\prime \prime}(t)$ function is given by the time integral of the rate functions,

$$
R_{T}=f^{\prime} b I\left(k / k_{1}+2 k_{3} K[N]+D K[B]\right)
$$

where $\mathrm{D}=\mathrm{k}_{2} /\left(2 \mathrm{k}_{3} \mathrm{bI}_{0}[\mathrm{~N}] /[\mathrm{B}]+\mathrm{KM}\right)$.

We will consider special cases.

(i) $[N]=0$, for system $A / B$, using $[B]=[B] 0 \exp \left(-d^{\prime} t\right)$, with $d^{\prime}=\left(k_{2} / k_{1}\right) b I_{0}$, solving Eq. (17) leads to the efficacy

$C E(1)=1-G[B]_{0} H(t) \exp (-G t)$

where, $H(t)=\left[1-\exp \left(-D^{\prime} t\right)\right] / D^{\prime}$, with $D^{\prime}=d^{\prime}-G^{\prime}, G^{\prime}=d^{\prime}-\left(k_{2} / k_{1}\right) G, G=\left(1-f^{\prime}\right)\left(k / k_{1}\right) b I_{0}, f^{\prime}=\left(k_{2} / k_{1}\right)[B]_{0} /[A]_{0}$ is a correction factor. We note that $\mathrm{GH}$ has astaedy state value of $\mathrm{G} / \mathrm{D}^{\prime}$, which is independent to the light intensity ( $\mathrm{I}$ ) , and at high intensity and for large time, the efficacy approaches to one. The CE has a transient state of $1+G[B]_{0}(t-1)(1-G t)$, a nonlinear increasing function ot time $(t)$.

(ii) $[B]=0$, for system $A / N$, the time integral of Eq. (17), or (18) using $[N]=[N]_{0} \exp (-d t)$, leads to

$$
\begin{aligned}
& C E(2)=1-\exp \left(-E^{\prime \prime}\right) \\
& E^{\prime \prime}(t)=G t+2 b I_{0} k_{3}[N]_{0}[1-\exp (-d t)] / d
\end{aligned}
$$

where, the $C E(2)$ has a transient state of , when 1- $\exp \left(-\mathrm{E}^{\prime \prime}\right)=\mathrm{E} "(\mathrm{t})=\left(\mathrm{G}+2 \mathrm{k}_{3} \mathrm{bI}_{0}[\mathrm{~N}]_{0}\right) \mathrm{t}$

(iii) 3-component system of $\mathrm{A} / \mathrm{B} / \mathrm{N}$, Eq. (17) can be solved only numerically. However, it might be approximated by the sum of Eq. (19) $\mathrm{m}$ for $[\mathrm{N}]=0$ and Eq. (2), for $[\mathrm{B}]=0$, leading to a total efficacy given by $C E($ total $)=C E(1)+C E(2)$, which has a transient state proportional to $1+G[B] 0(t-1)(1-G t)+G$ $\left.+2 \mathrm{k}_{3} \mathrm{bI}_{0}[\mathrm{~N}]_{0}\right) \mathrm{t}$, or the sum of $[\mathrm{A}]_{0},[\mathrm{~B}]_{0}$. and $[\mathrm{N}]_{0}$, but in ahighly nonlinear format. We note that $\mathrm{G}=(1-$ $\left.\mathrm{f}^{\prime}\right)\left(\mathrm{k} / \mathrm{k}_{1}\right) \mathrm{bI} \mathrm{I}_{0}$, with $\mathrm{f}^{\prime}=\left(\mathrm{k}_{2} / \mathrm{k}_{1}\right)[\mathrm{B}]_{0} /[\mathrm{A}]_{0}$ is a correction factor, so $\mathrm{G}$ is an increasing function of $[\mathrm{A}]_{0 .}$.

The $\mathrm{CE}$ is also proprotional to th linear power of $\mathrm{bI}$. We note that this feature is based on the case for type-II dominant, and bimolecular termination, the $\mathrm{k}^{\prime} \mathrm{R}^{2}$ term in Eq. (6), is much weaker than the coupling terms of k"SR and KMR, such that the solution of Eq. (6) leads to that R is proportional to $\mathrm{bI}[\mathrm{A}\}$. In contrast, for a strong bimolecular termination case, $\mathrm{R}$ is proportional to the squrae root of $\mathrm{bI}[\mathrm{A}\}$, and the steady-state $\mathrm{CE}$, or E" in Eq. (24) is proportional to $[\mathrm{A}]_{0} /\left(\mathrm{bI}_{0}\right)^{0.5}$, such that higher light intensity has a lower steady-state CE, whereas it has a faster rising time profile. [20-22].

\subsection{General features and Analysis of measured results}

As shown by Eqs. (21) to (25) the following significant features of the 3-components system $\mathrm{A} / \mathrm{B} / \mathrm{N}$ are summarized. The conversion efficacy (CE) defined by $\mathrm{CE}=1-\mathrm{M} / \mathrm{M}_{0}$, which is proprotional 
to the sum shown by Eq. (25), $\mathrm{E}^{\prime \prime}=\mathrm{bI}_{0}\left(\mathrm{k}[\mathrm{A}]_{0}+\mathrm{KD}[\mathrm{A}]_{0}[\mathrm{~B}]_{0}+\mathrm{KD}{ }^{\prime}[\mathrm{A}]_{0}[\mathrm{~B}]_{0}[\mathrm{~N}]_{0}\right)$. The measured data of Table 2 of Rahal et al [19] can be easily analyzed based on Eq. (21) to (25) as follows.

(i) Without [A], Iod/NPG alone has very weak FRP, in which its light absorption could also produce of radical for FRP. However, it is much weaker than the [A] initiated FRP. Therefore, our modeling ignores the coupling of excited state of Iod/NPG and the monomer.

(ii) As shown by Table 2 of Rahal et al [19], the monomer conversion (CE) depends not only on the property of the additives $[\mathrm{B}]$ and $[\mathrm{N}\}$, but also the types of monomers (TMPTA,or MA). In some monomers, $[\mathrm{A}] / \mathrm{NPG}$ is more efficient than $[\mathrm{A}] / \mathrm{Iod}$, but revserse trend occurs in some monomers. However, 2-component systems (with $\mathrm{CE}=0 \%$ to $80 \%$ ) are always less efficient than that of 3component systems (with CE $=70 \%$ to $86 \%$, in TMPTA). The initiator (coumarin) shows a dual photo-oxidation and photo-reduction charcter for high efficacy. Examples are shown as follows.

(iii) In $[\mathrm{A}] / \mathrm{Iod}$ system (with $\mathrm{N}=0), \mathrm{CE}=\mathrm{E}^{\prime \prime}=\mathrm{bI}_{0}[\mathrm{~A}]_{0}\left(\mathrm{k}+\mathrm{KD}[\mathrm{B}]_{0}\right)$, which depends on the types of $[\mathrm{A}]$ (or Coumarin). As reported by Rahl etal [19]), when [A]=CoumC, a strong photo-oxidation for high FRP, with $C E=60 \%-80 \%$, In contrast, when $[A]=C o u m B, C E=0 \%$, an opposite behavior with strong photo-reduction process, in which the low rate of FRP can be also due to the strong OIE [25], which also reduces the radical (R). In some 3D systems, this OIE was pre-eliminated by a red-light [22].

(ii) In $[\mathrm{A}] / \mathrm{NPG}$ system (with $[\mathrm{B}]=0), \mathrm{CE}=\mathrm{E}=\mathrm{kbI}[\mathrm{A}]_{0}$, which theoretically should be always less efficient than $[\mathrm{A}] /$ Iod system. However, for a strong photo-oxidation such as $[\mathrm{A}]=\mathrm{CoumB}, \mathrm{CE}=(60 \%$ to $80 \%$ ) in CoumB/NPG vs. $\mathrm{CE}=0 \%$ in CoumB/Iod, but it still lower than that of 3.-component system CoumA/Iod/NPG (with CE $=78 \%$ to $88 \%$ ).

\section{Conclusion}

This article presents, for the first time, the kinetics and the general conversion features of a 3component ([A], $[\mathrm{B}]$ and $[\mathrm{N}])$ system, based on proposed mechanism of Rahal et al [19]. Without initiator [A], Iod/NPG alone has very weak FRP. The additives [B] (or Iod) and N (or NPG) have triple functions of: (i) regeneration of [A] via couplings terms [B][C] and S[B]; (ii) direct producing of radical $(R)$ via coupling of $T$ and $[B]$; and (iii) indirect producing of radical (R) via the coupling of $[B]$ and radicals (S and S') produced by additive $[\mathrm{N}]$ (or NPG). The monomer conversion efficacy depends on the property of the additives and also the types of monomers. In some monomers, A/NPG is more efficient than A/Iod, but revserse trend occurs in some monomers. However, 2-component systems are always less efficient than that of 3-component systems fro all types on monomers.To conclude, the measured results of Rahal et al [19] are well analyzed and matching the predicted features of our modeling. Analytical formulas for the role of each component concentration, light intnesity and coupling rates on the conversion efficacy are derived.

Funding: The Agence Nationale de la Recherche (ANR agency) is acknowledged for its financial support through the NoPerox grant.

Acknowledgments: JTL thanks the internal grant of New Vision Inc. and DCC thanks the financial support from 359 China Medical University with the grant number CMU109-S-39.

Conflicts of Interest: Jui-Teng Lin is the CEO of New Vision Inc.

\section{References}


1. Fouassier, J. P. \& Lalevée, J. Photoinitiators for Polymer Synthesis-Scope, Reactivity and Efficiency. Wiley-VCH Verlag GmbH \& Co. KGaA: Weinheim, Germany, 2012.

2. Yagci, Y., Jockusch, S. \& Turro, N.J. Photoinitiated polymerization: Advances, challenges and opportunities. Macromolecules 43, 6245-6260 (2010).

3. Ligon, S.C.; Liska, R.; Stampfl, J.; Gurr, M.; Mulhaupt, R. Polymers for 3D printing and customized additive manufacturing. Chem. Rev. 2017, 117, 10212-10290.

4. Shusteff, M.; Browar, A.E.M.; Kelly, B.E.; Henriksson, J.; Weisgraber, T.H.; Panas, R.M.; Fang, N.X.; Spadaccini, C.M. One-step Volumetric Additive Manufacturing of Complex Polymer Structures. Sci. Adv. 2017, 3, 7.

5. Kelly, B.E.; Bhattacharya, I.; Heidari, H.; Shusteff, M.; Spadaccini, C.M.; Taylor, H.K. Volumetric Additive Manufacturing via Tomographic Reconstruction. Science 2019, 363, 1075-1079.

6. de Beer, M.P.; van der Laan, H.L.; Cole, M.A.; Whelan, R.J.; Burns, M.A.; Scott, T.F. Rapid, Continuous Additive Manufacturing by Volumetric Polymerization Inhibition Patterning. Sci. Adv. 2019, 5, 8 .

7. van der Laan, H.L.; Burns, M.A.; Scott, T.F. Volumetric Photopolymerization Confinement through Dual-Wavelength Photoinitiation and Photoinhibition. ACS Macro Lett. 2019, 8, 899-904.

8. Scott, T.F.; Kowalski, B.A.; Sullivan, A.C.; Bowman, C.N.; McLeod, R.R. Two-Color Single-Photon Photoinitiation and Photoinhibition for Subdiffraction Photolithography. Science 2009, 324, 913-917.

9. Lin J.T.; Chen K.T.; Cheng D.C.; Liu, H,W. Dual-wavelength (UV and Blue) controlled photopolymerization confinement for 3D-printing: modeling and analysis of measurements. Polymers, 2019, 11, 1819.

10. Lin, J.T.; Liu, H.W.; Chen, K.T.; Cheng, D..C. 3-wavelength (UV, blue, red) controlled photopolymerization: improved conversion and confinement in 3D-printing. IEEE Access, 2020, 8, 49353-49362.

11. Dietlin, C.; Schweizer, S.; Xiao, P.; Zhang, J.; Morlet-Savary, F.; Graff, B.; Fouassier, J.-P.; Lalevée, J. Photopolymerization upon LEDs: New Photoinitiating Systems and Strategies. Polym. Chem. 2015, 6, 3895-3912. [CrossRef]

12. Pigot, C.; Noirbent, G.; Brunel, D.; Dumur, F. Recent advances on push-pull organic dyes as visible light photoinitiators of polymerization. Eur. Polym. J. 2020, 133, 109797.

13. Garra, P.; Dietlin, C.; Morlet-Savary, F.; Dumur, F.; et al Redox two-component initiated free radical and cationic polymerizations: Concepts, reactions and applications. Progress in Polymer Science, 2019, 94, pp.33-56. 10.1016/j.progpolymsci.2019.04.003

14. Noirbent, G.; Dumur, F. Recent Advances on Copper Complexes as Visible Light Photoinitiators and (Photo) Redox Initiators of Polymerization. Catalysts, MDPI, 2020, 10, 10.3390/catal10090953.

15. Mokbel, H.; Anderson, D.; Plenderleith, R.; Dietlin, C.; et al. Simultaneous initiation of radical and cationic polymerization reactions using the "G1" copper complex as photoredox catalyst: Applications of free radical/cationic hybrid photopolymerization in the composites and 3D printingfields. Prog. Org. Coat., 132, 50-61 (2019). DOI: 10.1016/j.porgcoat.2019.02.044 
16. Lin, J.T.; Lalevee, J.; Cheng, D.C. Kinetics analysis of copper complex photoredox catalyst: roles of oxygen, thickness, and optimal concentration for radical/cationic hybrid photopolymerization. Polymers (2021, in press),

17. Abdallah, A.; Hijazi,A.; Lin, J.T.; Graff, B.; Dumur, F.; Lalevee, J. Coumarin Derivatives as Photoinitiators in Photo-Oxidation and Photo-Reduction Processes and a Kinetic Model for Simulations of the Associated Polymerization Profiles. App Polymer Material. 2020, 2,27692780.

18. Rahal, M.; Mokbel, H.; Graff, B.; Toufaily, J.; Hamieh, T.; Dumur, F.; Lalevée, J. Mono vs. Difunctional Coumarin as Photoinitiators in Photocomposite Synthesis and 3D Printing. Catalyst 2020, 10, 1202. [CrossRef]

19. Rahal, M.; Mokbel, H.; Graff, B.; Toufaily, J.; et al. 3-Carboxylic Acid and Formyl-Derived Coumarins as Photoinitiators in Photo-Oxidation or Photo-Reduction Processes for Photopolymerization upon Visible Light: Photocomposite Synthesis and 3D Printing Applications. Molecules 2021, 26, 1753. https://doi.org/ 10.3390/molecules26061753.

20. Lin, J.T,; Lalevee, L.; Cheng. D,C. Synergetic kinetics of free radical and cationic photopolymerization in three co-initiators and two-monomers system. Polymers (2021, in press).

21. Lin, J.T.; Chen, K.T.; Cheng D.C.; Liu, H,W. Enhancing blue-light-initiated photopolymerization in a three-component system: kinetic and modeling of conversion strategies. J Polymer Research, 2021, 28:2.

22. Lin J.T.; Liu HW,; Chen KT,; Chiu YC, ; Cheng DC. Enhancing UV photopolymerization by a redlight pre-irradiation: kinetics and modeling strategies for reduced oxygen-inhibition. J Polymer Science, 2020,58, 683-691, DOI:10.1002/pol.20190201.

23. Lin, J.T,; Cheng, D.C. Modeling the efficacy profiles of UV-light activated corneal collagen crosslinking. PloS One. 2017;12:e0175002.

24. Lin, J.T. Kinetics of enhancement for corneal cross-linking: proposed model for a two-initiator system. Ophthalmology Research, 2019, 10(3): 1-6; Article no.OR.49970 DOI: 10.9734/OR/2019/v10i330109.

25. Lin, J.T,; Chen. K.T,; Cheng. D,C, photopolymerization: the role of oxygen inhibition, viscosity and induction time. Front. Chem. 2019, 7:760. doi: 10.3389/fchem.2019.00760. 